\title{
Peak Expiratory Flow Rate (PEFR)-A Simple Ventilatory Lung Function Test
}

\author{
Mridha MAA ${ }^{1}, \mathrm{Amin}_{\mathrm{MR}^{2}, \text { Kabir ARML }}^{3}$
}

\begin{abstract}
Peak expiratory flow rate (PEFR) is the maximal expiratory flow rate sustained by a subject for at least 10 milliseconds expressed in Litre per minute $(\mathrm{L} / \mathrm{min})$. PEFR is a simple, reliable, reproducible and easily measurable ventilatory lung function test. This simple test had been measured by various types and shapes of instruments for long since, now miniWright peak flow meter is widely used to measure the of PEFR values. Mini-Wright peak flow meter is cheap, easily portable and reproducible device for PEFR even below the age 5 years. Different countries use their own nomogram or prediction equation to find out mean PEFR values of particular height. Similarly, the prediction equation for calculation of PEFR values of Bangladeshi boys and girls are 5.96XHeight-495 and 5.70XHeight-479 respectively. Peak expiratory flow rate is very useful tool for diagnosis, management and follow up of reversible airway diseases.
\end{abstract}

Key words: Peak expiratory flow rate, lung function test, mini - Wright Peak Floww Meter

\section{Introduction}

Peak expiratory flow rate is the maximal expiratory flow rate sustained by a subject for at least 10 milliseconds expressed in Litre per minute (L/min) ${ }^{1,2,3}$. PEFR had been used as measurement of ventilatory capacity for long since mainly because of a much simpler and less tiring procedure than maximum voluntary ventilation (MVV), single forced expiration in a simplified device min-Wright peak flow meter is now required and easily available for measurement of its value $e^{4,5}$.

\section{Physiological Consideration and Historical Background}

The basis of most of the various single-breath methods is the same which is the volume of air expired is measured against time by means of a spirometer with either a recording drum or a timing device. There are some differences of opinion about the most suitable interval of time over which to measure the volume and about the relative merits of a recording drum or a timing device, but it is generally agreed that methods of this kind are clinically valuable and give results, which are comparable with those of the MVV. All the methods, however, suffer from the disadvantage that the necessary apparatus is cumbersome and normally requires connection to an electric supply. Attention has therefore been directed to the possibility of using the maximum forced expiratory flow rate or "peak flow rate", instead of what is in effect the average for a limited time, as a measure of ventilatory capacity; such a measurement seemed likely to lend itself to the use of a simpler instrument, consisting merely of a flow meter with a device for recording the maximum flow. The empirical use of a measurement of this kind is very old. "The physician asked a patient with respiratory disease to whistle or blow a candle out was crudely assessing the maximum respiratory velocities". Donald in 1953 suggested that a "simple, whistle-like instrument" might be developed and might become a standard clinical tool.

Later on the instrument, called a "pneumometer" incorporates an aneroid manometer fitted with a device for recording the maximum flow rate. Rates up to about 700 $\mathrm{L} / \mathrm{min}$ can be recorded. Pneumotachograph has led to many observations of the expiratory flow pattern, but no systematic attempt to use the peak flow rate as a physiological measurement in its own right appears to have been made. Pneumotachograph themselves have had very low resistances of the order of $2 \mathrm{~mm} . \mathrm{H}_{2} \mathrm{O} / 100 \mathrm{~L} / \mathrm{min}$ which gave a linear relationship between flow and pressure. Both the earlier and the latest forms of pneumotachograph suffer from the disadvantage of being fairly complicated and not easily portable. A much simpler and more robust and portable instrument, designed specifically for measuring the peak flow rate, called by them the "puff meter". Wright and McKerrow described the peak flow meter ${ }^{6}$. Since that time the instrument has been used widely and has been found reliable over long

1. Dr. Md. Al-Amin Mridha, Assistant Professor, Department of Paediatrics, Shaheed Suhrawardy Medical College, Sher-E-Bangla Nagar, Dhaka.

2. Prof. Md. Ruhul Amin, Professor and Head, Department of Paediatric Pulmonology, Bangladesh Institute of Child Health, Sher-E-Bangla Nagar, Dhaka.

3. Prof. ARM Luthful Kabir, Professor, Department of Paediatrics, Sir Salimullah Medical College \& Hospital, Dhaka. 
periods. The Wright peak flow meter depends upon the rotation of a vane attached to a spiral spring. Movement of the vane uncovers an annular orifice and the point at which pressure behind the vane balances the force of the spring depends upon the flow rate. The standard Wright's peak flow meter ranges from 50-1000 L/min and weight 900 $\mathrm{gm}^{6}$. Later on various portable smaller and cheaper instruments suitable for domiciliary practice have been developed. The peak flow gauge (Ferraris Development and Engineering Co. Ltd, London N18 3JD, UK) correlates closely with the $\mathrm{PFM}^{7}$ but is too bulky to be carried easily. The pulmonary monitor ${ }^{8}$ is pocket-sized, reliable and gives reproducible values that correlate well with the PFM. Unfortunately the monitor has a scale differing from the standard PFM. This would make comparison between trials difficult. Lastly a mini-Wright peak flow meter has become available (Airmed, Clement Clarke International Ltd, Airmed House, Edinburgh Way, Harlow, Essex CM20 2ED $\mathrm{UK})^{9}$.

\section{Mini-Wright Peak Flow Meter (mWPFM)}

This instrument is simpler version of the Wright peak flow meter now used worldwide. Measurements with this instrument correlate well with peak expiratory flow rate measurements from the larger Wright peak flow meter (AirMed, Ltd., Harlow, England), with observed correlation generally higher than $0.90^{10}$. The instrument is a light plastic Cylinder measuring $15 \times 5 \mathrm{~cm}$ weighing $72 \mathrm{gm}$ (without mouth piece). It consists of a spring piston that slides freely on a rod within the body of the instrument. The piston drives an independent sliding indicator along a slot marked with a scale graduated, low range from 50-350 $\mathrm{L} / \mathrm{min}$ and high range from $60-800 \mathrm{~L} / \mathrm{min}$. The indicator records the maximum movement of the piston, remaining in that position until return to zero by the operator. In use the machine must be held horizontally with air vents uncovered $^{11}$. The instrument may be cleaned easily in running water or in a detergent solution. Details of washing and sterilization methods are supplied in leaflet along with the meter. Studies involving long-term use of this device, particularly the mini-Wright peak flow meter, has demonstrated that performed well for many months and with as may as 4000 blows $^{12,13}$. Performance of accuracy of the mini-Wright peak flow meter meets national asthma education programme (NAEP) guideline variation $< \pm 5 \%$ with standard Wright peak flow meter ${ }^{14}$.

Factors affecting the Peak Expiratory Flow Rate (PEFR) Anthropometric measurements: Standing height is the best single predictor in childhood for PEFR. It has more or less linear relationship with weight, body surface area and chest expansibility $^{15,16}$.

Age and Sex: Age has linear relationship with PEFR but sex has no significant relation with PEFR in children when height is considered ${ }^{17}$. But age has curvilinear in male and linear relationship in female of adult ${ }^{18}$. When only age is considered, PEFR differs in both sexes ${ }^{19}$.

Malnutrition: Current malnutrition impairs the $\mathrm{PEFR}^{20}$ and chronic malnutrition is associated with reduction in PEFR/Age, perhaps because of slow growth of the large airways $^{21}$.

Environmental effect: Smoking and environmental tobacco smoke increases airway variability, thereby affect pulmonary function test as a PEFR ${ }^{22,23}$. Summertime particulate air pollution has independent effect on PEFR and is associated with decline in PEFR in children ${ }^{24,25}$.

Respiratory tracts and thoracic cage: The PEFR occurs early in the expiration and is dependent on personal effort, large airway resistance and possible compressive effect of the maneuver on the intrathoracic airway ${ }^{26,27}$. Thoracic cage deformity and respiratory tract infection including microfilaremia has adverse effect on $\mathrm{PEFR}^{28}$.

\section{Use of mini-Wright peak flow meter}

The purpose and technique of the test should be explained to the subject followed by a demonstration of its performance. Person should perform the test in standing position holding the peak flow meter horizontally without interfering with the movement of the marker (arrow) or covering the slot. He or she should asked to take deep breath then exhale it by forceful expiration as fast as possible after maintaining air tight seal between lip and mouth piece of the instrument. Reading should be taken keeping the instrument horizontal position ${ }^{29}$. Besides this, distributor of mini-Wright peak flow meter supply leaflet, which contains detail procedure with demonstration. The process of daily recording of PEFR has depicted clearly 9

\section{Clinical interpretation of values of PEFR}

Personal based value of PEFR can be compared to normal reference population and also with predicted value from regression equation ${ }^{30,31}$. School-based study at Dhaka has produced the prediction equation for calculation of PEFR values of Bangladeshi boys, 5.96XHeight-495 and girls, PEFR $=5.70 X$ Height-479. Besides this formula ${ }^{1}$, PEFR values of Bangladeshi boys and girls can be ready find out by using nomogram. Similar type of nomogram had been used to find out PEFR of different country ${ }^{32,33,34}$.

Diurnal variation in PEFR is a good indicator of circadian bronchial labiality responsiveness. PEFR record with diurnal variation of $20 \%$ or more is a good clinical and occupational indicator of asthma ${ }^{35,36}$.

PEFR variability- diurnal variation in peak flow rate expressed as the formula as follows ${ }^{37}$.

Daily variability $=\frac{\text { HighestPEFR }- \text { LowestPEFR }}{\text { HighestPEFR }} \times 100$ 
Bronchial provocation test by exercise in 'exercise induced asthma' is diagnostic when PEFR falls $15 \%$ of personal based after exercise and reversibility of airway obstruction is evidenced by an increased in PEFR more than $20 \%$ after an adequate dose of nebulised bronchodilator is diagnostic for asthma ${ }^{38}$. Peak expiratory flow rate morning-to-evening variation ? $20 \%$ is consistent with asthma ${ }^{39}$.

Self-management of bronchial asthma is advised to maintain a peak flow chart and personal based result should be interpreted as green zone (safe zone) 80 to $100 \%$ of personal best result, yellow zone zone of alert) $<80 \%$ to $>50 \%$ of personal best result, red zone (zone of emergency)- $<50 \%$ of personal best result ${ }^{37}$

PEFR can be used as treatment scheme of asthma. The important element of this scheme is as follows: If the PEFR is $70 \%$ of personal best, then maintenance regimen of twice daily inhaled bronchodilator and inhaled corticosteroid is continued. A value $<70 \%$ of personal best result requires a period of doubling of the inhaled corticosteroid dose. At $<50 \%$ of personal best result, a course of oral steroid is triggered, and the patient makes telephone contact with the physician ${ }^{5}$.

Peak flow monitoring especially valuable for detecting deterioration of asthma, for predicting acute exacerbation of asthma and its management. Availability of peak flow measurement not only allows formulation of a management plan with criteria for both intensification of therapy and recourse to medical assistance. Regular measurement of peak flow allows objective determination of effect of therapy ${ }^{40,41}$. Peak flow measurement can be used to titrate maintenance treatment and deserve wider use in monitoring the adequacy of treatment of asthma ${ }^{42}$.

PEFR is highly sensitive and accurate index of airway obstruction. It can be used as a guideline of admission and discharge of asthma when PEFR value $>60 \%$ of expectedadmission is probably unnecessary, $40-60 \%$ of expectedconsider admission and $<40 \%$ of expected- admission is probably necessary ${ }^{43}$. Peak flow measurement is sensitive indicator to measure the strength of muscles of respiration ${ }^{44}$. So, serial measurement of PEFR in Guillain-Barre syndrome or progressive flaccid paralysis to predict the involvement of respiratory muscle is clinically important to give warning of the hypoventilation and need for ventilator support ${ }^{45}$.

\section{Conclusion}

Use of peak expiratory flow rate as a measurement of ventilatory function test is an ancient. This simple test, measured by mini-Wright peak flow meter, is very useful in diagnosis, management, follow up of bronchial asthma and predict the status of ventilator lung function.

\section{References}

1. Mridha MA, Ruhulamin M. Peak expiratory fow rate in normal school children of Dhaka city, Bangladesh. Bangladesh J Child Health 2002; 26(3/4):46-51

2. Neuspiel DR, Mosenifar Z. Peak flow rate measurement. Emedicine.medscape.com/article/1413347; updated March 2011

3. Jain SK, Kumar R, Sharma DA. Peak expiratory flow rate in relation to anthropometric measurements in normal Indian subjects. East Afr Med J 1982 ; 59(9): 593-598

4. Brown LA, Sly RM. Comparison of mini-Wright and standard Wright peak flow meters. Ann Allergy 1980; 45: 72-74

5. Cross D, Nelson HS. The role of the peak flow meter in the diagnosis and management of asthma. J Allergy Clin. Immunol 1991; 87(1): 120-128.

6. Wright BM, McKerrow CB. Maximum forced expiratory flow rate as a measure of ventilatory capacity. Br Med J 1959; 21: 1041-1047

7. Bhoomkar A, Davies S, Geary M, Hills EA. Comparison of peak flow gauge and peak flow meter. Thorax 1975; 30: 225-227

8. Perks WH, Cole M, Steventon RD, Tams IP, Prowse K. An evaluation of the vitalograph Monitor. Br J Dis Chest 1981; 75: 161-164

9. Wright BM. A miniature Wright peak flow meter. Br Med J 1978; 2: 1627-1628

10. Levin E, Gold MI. The mini-Wright expiratory flow meter. Can Anaesth Soc J, 1981; 28(3): 285-287

11. Perks WH, Tams IP, Thompson DA, Prowse K. An evaluation of the mini Wright peak flow meter. Thorax 1979; 34: 79-81

12. Burns KL. An evaluation of two inexpensive instruments for assessing airway flow. Ann Allergy 1979; 43: 246-249

13. Primhak RA, Biggins JD, Tsanakas JN, Hatzimichael A, Milner RDG, Karpouzas JG. Factors affecting the peak expiratory flow rate in children. $\mathrm{Br}$ J Dis Chest 1984; 78: 26-35

14. Chowgule RV, Shetye VM, Parmar JR. Lung function tests in normal Indian children. Indian Pediatr 1995; 32(2): 185-191

15. Nairn JR, Bennett AJ, Andrew JD, Macarthur P. A study of respiratory function in normal school children; the peak expiratory flow rate. Arch. Dis Child 1961; 36: 253-260

16. Malik SK, Jindal SK, Banga N, Sharda PK, Gupta HD. Peak expiratory flow rate of healthy North Indian teachers. Indian J Med Res 1980; 71: 322-324

17. Carson JWK, Hoey H, Taylor MRH. Growth and other factors affecting peak expiratory flow rate. Arch Dis Child 1989; 64: 96-102

18. Primhak RA, Coates FS. Malnutrition and peak expiratory flow rate. Eur Respir J 1988;1: 801-803

19. Carswell F, Hellier J, Harland PS, Meakins RH. Peak expiratory flow rate and malnutrition. Trans R Soc Trop Med Hyg 1980; 74(6): 814-816

20. Fielder HMP, Lyons RA, Heaven M, Morgan H, Govier P, Hooper M. Effect of environmental tobacco smoke on peak flow variability. Arch Dis Child 1999; 80: 253-256

21. Frischer T, Khur J, Meinert R, Stat D, Karmaus W, Urbanek R. Influence of maternal smoking on variability of peak expiratory flow rate in School children. Chest, 1993; 104(4): 1133-1137

22. Neas LM, Dockery DW, Burge H, Koutrakis P, Speizer FE. Fungus spores, air pollutants and other determinants of peak expiratory flow rate in children. Am J Epidemiol 1996; 15:143(8): 797-807

23. Neas LM, Dockery DW, Koutrakis P, Tollerud DJ, Speizer FE. The association of ambient air pollution with twice daily peak expiratory flow rate measurements in children. Am J Epidemiol Jan 1995; 15; 141(2): 111-122

24. Swaminathan S. Pulmonary function testing in office practice. Indian J Pediatr 1999; 66:905-914

25. Pfaff JK and Morgan WJ. Pulmonary function in infants and children. Respiratory Medicine. Padiatric Clinincs of North America 1994; 41(2): 401-423

26. Enarson DA. Microfilaremia and peak expiratory flow rate. Trop Geogr Med. 1984; 36(1): 17-20

27. Gregg I and Nunn AJ. Peak expiratory flow in symptomless elderly smokers and ex-smokers. Br Med J. 1989; 22; 298:1071-1072 
28. Pande AH. Prediction of peak expiratory flow rate from height and weight. Indian J Pediatr. 1986; 53(4): 521-523

29. Nunn AJ, Gregg I. New regression equations for predicting peak expiratory flow in adult. Br Med J 1989; 198: 1068-1070

30. Benjaponpitak S,Direkwattanachai C,Kraisarin C,Sasisakulporn C. Peak expiratory rate values of students in Bangkok. J Med Assoc Thai. 1999;82 1:137-143.

31. Godfrey S, Kamburof PL, Nairn JR. Spirometry, lung volumes and air ways resistances in normal children aged 5-18 years. Br J Dis Chest 1970; 64: 15-24

32. Uduphille-M. Peak flow rate in Srilankan school going children of Sinhalese ethnic origin. Respir Med 1994; 88(3): 219-227

33. Lebowitz MD. The use of peak expiratory flow rate measurements in respiratory disease. Pediatr Pulmonol 1991; 11: 166-174

34. Sly PD, Hibbert ME, Sci MP, Landau LI. Diurnal variation of peak expiratory flow rate in asthmatic children. Pediatr pulmonol 1986; 2(3): 141-146 35. Hassan MR, Hossain MA, Mahmud AM, Kabir ARML, Ruhulamin M, Bennoor KS. National asthma guidelines for medical practioners. Asthma Assocation of Bangladesh. IDCH campus, Mohakhali, Dhaka 1999; 73-94

36. Silverman $\mathrm{M}$ and McKenzie S. Respiratory disorder, Bronchial provocation test. In: Campbel AGM, McIntosh N (eds), Forfar and Arneil's Textbook of Pediatrics 1998, 5th edn, 489-501. London, Churchill Livingstone 37. Andrew HL, Joseph D, Donald YML. Allergic disorder, Childhood asthma, PEF monitoring In:Behrman RE, Kliegman RM, Jenson HB (editors), Nelson Textbook of Pediatrics. 2004, 17th edition, 764-765.USA, WB Saunders Co.

38. Boggs PB, Wheeler D, Washburne WF, Hayati F. Peak expiratory flow rate control chart in asthma care: chart construction and use in asthma care. Ann Allergy Asthma Immunol. 1998; 81(6): 552-562

39. Jose M, Garcia I, Santos PG. Asthma self management education program by home monitoring of peak expiratory flow. Am J Respir Crit Care Med 1995; 151:353-359

40. Brouwer AF, Brand PL. Asthma education and monitoring: what has been shown to world. Paediatr Respir Rev. 2008;9(3):193-9

41. Taylor MR. Asthma: audit of peak expiratory flow rate guidelines for admission discharge. Arch. Dis Child 1994; 70(5): 432-434

42. Lockhart W, Smith DH, Mair A, Wilson WA. Practical experience with the peak flow meter. Br Med J 1960 2: 37-38

43. Brown JK, Minns RA. Disorder of the central nervous system, Diseases of the peripheral nervous system In: Campbel AGM, McIntosh N (editors), Forfar and Arneil's Textbook of Pediatrics1998, 5th edn, 725-726. London, Churchill Livingstone

44. Brouwer AF, Brand PL. Asthma education and monitoring: what has been shown to work. Paediatr Respir Rev. 2008;9(3):193-9

45. Lebowitz MD, Knudson RJ, Robertson G, Burrows B. Significance of individual changes in maximum expiratory flow volume and peak expiratory flow measurements. Chest 1982; 81: 566-570 